\title{
CULTURA TEXTOVISUAL, HIBRIDACIÓN Y DIALOGISMO EN LA OBRA DE ALBERT SOLOVIEV ${ }^{1}$
}

TEXTVISUAL CULTURE, HYBRIDIZATION AND DIALOGISM IN THE WORK OF ALBERT SOLOVIEV

\section{ABSTRACT}

Defying the traditional philological channels, the short short story broadens in the digital world beyond writing; it brings together the iconicity of mass media and assembles literary materials with those coming from other systems of non-linguistic meaning. Significant plurality expands the aesthetic resonance of cultural imaginary and emphasizes dialogism, intertextuality, intermediality, hybridity and ambiguity; the reader is confronted with a polyartistic and multisensory experience, where words, by engaging with others artistic forms, acquire a new narrative and aesthetic dimension.

Keywords: textualvisual culture, hypermedial short short story, Albert Soloviev, illustration, hybridization.

\footnotetext{
${ }^{1}$ Este trabajo se encuadra dentro del Proyecto de Investigación I+D+I «MiRed (Microrrelato hipermedial español e hispanoamericano (2000-2020). Elaboración de un repositorio semántico y otros desafíos en la red» (RTI2018-094725-B-I00), financiado por el Ministerio de Ciencia, Innovación y Universidades y el Fondo Europeo de Desarrollo (FEDER), en la convocatoria 2018 dentro del marco del Plan Estatal de I+D+I Orientada a los Retos de la Sociedad.
} 


\section{RESUMEN}

Desafiando los cauces filológicos tradicionales, el microrrelato se ensancha en la red más allá de la escritura; aglutina la iconicidad de los medios de comunicación de masas y ensambla los materiales literarios con los procedentes de otros sistemas de significación no lingüística (fotográfico, pictórico, musical, audiovisual, etc.) e integra distintas textualidades y manifestaciones artísticas. La pluralidad significativa amplía la resonancia estética del imaginario cultural y enfatiza el dialogismo, la intertextualidad, la intermedialidad, el hibridismo y la ambigüedad; el lectoespectador está ante una experiencia poliartística y multisensorial, donde las palabras, al engranarse con otras formas artísticas, adquieren una nueva dimensión narrativa y estética.

Palabras clave: cultura textovisual, microrrelato hipermedial, Albert Soloviev, ilustración, hibridación.

Fecha de recepción: 20 de junio de 2019.

Fecha de aceptación: 8 de julio de 2019.

Cómo citar: Calvo Revilla, Ana (2019): «Cultura textovisual, hibridación y dialogismo en la obra de Albert Soloviev», en Actio Nova: Revista de Teoría de la Literatura y Literatura Comparada, 3: 532-555.

DOI: https://doi.org/10.15366/actionova2019.3.022 


\section{LA CULTURA TEXTOVISUAL DENTRO DEL PARADIGMA CULTURAL} CONTEMPORÁNEO

Desde que el romanticismo del Athenaeum propuso -como expresa el intelectual francés Maurice Blanchot en La conversación infinita- el resquebrajamiento del todo no "para dificultar la comunicación, sino para hacerla absoluta" (2008: 460-461) y promovió la discontinuidad como forma, cobraron fuerza dentro del panorama cultural y literario las formas breves y fragmentarias, las cuales conquistan el silencio, sustituyen las relaciones sintagmáticas por la yuxtaposición abrupta y sincopada y enfatizan el carácter inacabado de la obra y su naturaleza.

Aunque la velocidad y la estructura reticular en la que estamos sumergidos pueden llevarnos a pensar que la brevedad y la fragmentariedad son cualidades estéticas de la contemporaneidad, constituyen una imagen especular de la conciencia humana que se adapta a la discontinuidad del pensamiento, prolongan la estética de la oralidad y respetan los cauces naturales por los que transcurre la comunicación. Ambos rasgos, considerados por algunos críticos como configuradores de la obra literaria hipertextual en todas las modalidades genérica, revelan la conciencia de lo múltiple.

Dado que cada época histórica percibe la realidad de una manera distinta (Wölfflin, 2011: 33), el pensamiento contemporáneo ha experimentado un giro hacia la cultura textovisual -el giro pictórico y visual de W. J. T. Mitchell ${ }^{2}$ - El homo videns comprende la realidad y la narra de manera multimedia y los géneros literarios se expanden más allá de lo escrito a través de creaciones simbióticas, presididas por la lingüística de la imagen y por la iconología del texto, en las que texto e imagen pueden ser contempladas con un solo golpe de vista en una unidad perceptiva. Al multiplicarse los lenguajes «en un nivel de simbiosis e hibridación inimaginable hace veinte años» (Carrión, 2011: 46), aparecen códigos artísticos de gran complejidad semiótica. La realidad textual se muestra como una multiplicidad de formas (Barthes, 2009: 89), donde los códigos semióticos, culturales o simbólicos se entretejen y la hibridación se convierte en un espejo del rechazo de la homogeneización y de la reclamación de lo marginal, como un intento de romper los perímetros y límites establecidos y de buscar el umbral.

\footnotetext{
${ }^{2}$ Lo definió como «a postlinguistic, postsemiotic rediscovery of a picture as a complex interplay between
} visuality, apparatus, institutions, discourse, bodies, and figurality» (Mitchell, 1994: 16). 
Al mismo tiempo, la interacción entre distintos ámbitos de la creación literaria y artística (cine, diseño, animación, etc.) no se puede desligar de las mutaciones sociales y culturales emergentes en la red (Manovich, 2005). Dado que la tecnología digital lo textualiza todo y que los soportes digitales actúan como transmisores de la cultura y como espacios dialógicos entre las prácticas artísticas, nos encontramos no solo ante la transformación de los códigos sígnicos tradicionales en digitales (re-mediación) y de los formatos analógicos en digitales, sino también ante cambios paradigmáticos en la configuración del saber, en la representación de la realidad y en la esfera de la creación artística. La convergencia digital ha reorganizado el acceso a los bienes culturales, ha alterado los modos hegemónicos con que se configura la representación de lo real y ha desestabilizado los sistemas de referencia (Borràs, 2005: 274); ha propiciado la consolidación de un paradigma estético, predominantemente visual ${ }^{3}$ y ha activado la participación creativa, analítica y crítica de un receptor, que ha de articular la comunicación multimedia en dicho escenario, hasta el punto de que los textos, las imágenes y su digitalización no son islas separadas ni en la esfera de la creación ni en la de la recepción (Romero López, 2012: 273) ${ }^{4}$. El texto se muestra como una unidad de comunicación multisemiótica, que se sustenta en una práctica sociodiscursiva significante y se inserta en una o varias redes textuales con las que interactúa.

En consecuencia, es preciso abordar este cambio de paradigma con un lenguaje crítico adecuado y formular una teoría del discurso de la retórica hipermedia desde «un significado pragmático y performativo», pues la «forma deja de prestarse a un análisis puramente estilístico para ofrecer una proyección significativa» (Vouillamoz, 2000: 145).

\section{MICRORRELATO HIPERMEDIAL, INTERMEDIALIDAD Y MULTIMEDIALIDAD}

Desafiando los cauces filológicos tradicionales, el microrrelato se ensancha en la red más allá de la escritura. El entorno virtual ha potenciado la integración de distintas textualidades (lenguaje, sonido e imagen) y el ensamblaje de los materiales literarios con los procedentes de otros sistemas de significación no lingüística (fotográfico, pictórico, musical,

\footnotetext{
3 Ya Steven Holtzmann (1994) precisó algunos rasgos configuradores de la estética digital, como la discontinuidad y la fragmentación discursiva; la interactividad; el dinamismo hermenéutico e interpretativo; los mundos etéreos y efímeros; o la formación de comunidades virtuales, entre otros.

${ }^{4}$ Como ha subrayado Élisabeth Routhier en la tesis doctoral que defendió en la Universidad de Montreal, los objetos mediales entablan relaciones entre distintas formas, conocimientos y materias en unos procesos que participan en la construcción de lo real y modifican nuestras percepciones (2017: 38).
} 
audiovisual, etc.), suscitando un sistema de representación expandida, que se resiste a la canonización literaria. La pluralidad significativa, que se deriva de la contaminación del texto literario con otros campos artísticos, amplía la resonancia estética del imaginario cultural y enfatiza "el dialogismo, la intertextualidad, la intermedialidad, el hibridismo y la ambigüedad" (López-Varela, 2011: 97).

Bajo la designación microrrelato hipermedial (Calvo Revilla, 2017; 2019) aludimos a dos fenómenos estrechamente relacionados: la intermedialidad y a la multimedialidad. A pesar de que la intermedialidad se ha convertido en un concepto controvertido, es una categoría crítica pertinente en el análisis de los productos artísticos que están configurados por el entrecruzamiento de medios audiovisuales y digitales (Müller, 2006: 99) y por la complejidad de las interacciones que entablan distintos materiales (Rajewski, 2005: 47) ${ }^{5}$. Siguiendo los trabajos recientes de Gil González y Pardo (2018), en los que revisan la formulación anterior de la intermedialidad (Gil 2012) ${ }^{6}$, esta categoría aúna tres fenómenos: la obra multimedial propiamente dicha, que manifiesta el máximo grado de copresencia directa e integración textual de medios, compartiendo un único soporte textual o editorial; la obra hipermedia, que remite a un hipertexto con enlaces a diferentes medios; y la variante transmedia que, con menor grado de integración textual, alude a textos dotados de cierta autonomía que están en distintos medios (Gil y Pardo, 2018: 23). No nos referimos a la intermedialidad intrínseca que presentan casi todos los lenguajes artísticos, sino a la intermedialidad extrínseca, que precisa:

una transmisión, una combinación, en segundo grado, no solamente entre códigos (la palabra, la imagen, el sonido...), soportes (el libro, la pantalla, el CDRom...) o tecnologías (las artes gráficas, la fotografía o la televisión...), sino entre medios institucionalizados en cuanto tales: entre literatura y música o entre las artes plásticas y las escénicas; entre novela y cine, entre cómic y pintura, entre teatro y danza. (Gil González y Pérez Bowie, 2017: 17)

La adaptabilidad del microrrelato a las posibilidades multimedia de la esfera digital ha multiplicado las interacciones entre los componentes textuales con los auditivos o visuales. Como ha puesto de relieve Daniel Escandell, la pantalla ha hecho de la imagen un

\footnotetext{
${ }^{5}$ Son tres las categorías que establece Irina Rajewski: a) transposición medial desde un medio a otro (adaptación cinematográfica de una novela); b) integración de medios tradicionales con medios multimedia, asociados a las nuevas tecnologías; c) tematización referencial a otros medios: intertextualidad (2005: 44 ss.).

6 Consideraba la intermedialidad como una categoría formal que abarca: cross-media (adaptación a otro medio), transmedia (expansión a otro medio) y multimedia (hibridación entre distintos medios).
} 
componente central (2014: 17) y ha posibilitado la simultaneidad de elementos texto-visuales y la incorporación de imágenes (fotografías, ilustraciones o dibujos); es este un fenómeno más habitual en las redes sociales y en la blogosfera que en las revistas digitales.

La relación del microrrelato con la imagen ha sido objeto de diversos estudios y enfoques, algunos de ellos algo genéricos (Millán Barroso, 2009; Delafosse, 2013). En 2008 Francisca Noguerol en un trabajo emblemático "Minificción e imagen: cuando la descripción gana la partida" partió del binomio clásico ekphrasis e hipotiposis para detenerse en este último fenómeno, que traslada a imágenes el contenido del texto y "conforma el icono a partir de las palabras" (2008: 187). Recientemente Teresa Gómez Trueba (2018) ha profundizado en las herramientas (concursos, talleres) y estrategias (pies de fotos que funcionan como microrrelatos); y Antonio Rivas (2018) ha analizado la interacción textovisual en el ámbito de la blogosfera.

La combinación de componentes semióticos visuales y textuales puede ser analizada desde enfoques temáticos o estilísticos y perspectivas variadas, como desde la teoría de la recepción o desde la interacción estética, que genera dentro de una construcción dinámica y plural un diálogo epistemológico (Albaladejo 2016: 52) ${ }^{7}$. Con frecuencia la imagen subraya alguno de los componentes de la estructura referencial textual; es esta una práctica bastante habitual en los microrrelatos que Patricia Esteban Erlés publica en Facebook. Nos detenemos en esta ocasión en el microrrelato "La abuela":

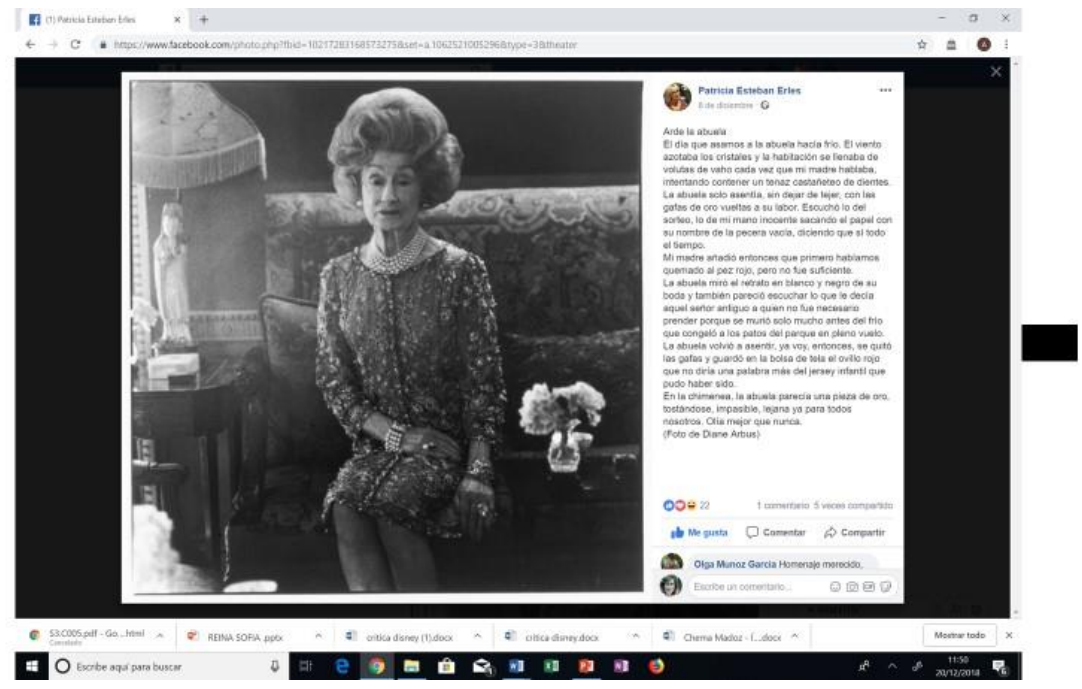

Figura 1

\footnotetext{
${ }^{7}$ Cecilia Silva-Díaz Ortega plantea que estas pueden ser de redundancia, complementariedad, contrapunto o contradicción (38-50).
} 
Comparten imagen y palabra la brevedad, la intensidad, la elipsis y la condensación expresiva. Las imágenes, gracias a sus valores representativos y simbólicos, condensan un alto valor semántico-conceptual y son un medio expresivo privilegiado. Según el modelo semiótico de Kress y van Leeuwen (2006), toda imagen tiene una triple función: representacional (representa la realidad de manera abstracta o concreta); interactiva o interpersonal (desata una cierta interacción comunicativa con el receptor) y composicional (establece significado a través de la posición, el encuadramiento en la página, o la nitidez, entre otros).

La hibridación semiótica más lograda la encontramos cuando, más allá de ser un motivo de inspiración recíproca, las representaciones visuales complementan, potencian, sustituyen o contradicen los valores semánticos derivados de los componentes textuales (Moebius 1986; Nodelman 1988; Sipe 1998; Agosto 1999; Gómez Trueba, 2018: 209)8. La transmisión de significado se convierte entonces en un proceso dinámico mediante la utilización de diferentes códigos semióticos (Kress y van Leeuwen 2001); mientras que la palabra se fundamenta en la lógica del discurso, que viene marcada por los conceptos de tiempo y secuencia, la lógica de la imagen responde a la presentación del espacio y a la simultaneidad (Kress 2003).

Con su gusto por lo monstruoso la escritora zaragozana acompaña el microrrelato de una fotografía de la escritora estadounidense Diane Arbus, quien con la tensión y extrañeza visuales (las imágenes representan a menudo seres marginales, gigantes, enanos, travestis) provoca la ruptura de los parámetros cognoscitivos habituales. Mientras la fotografía sumerge al espectador en una escena del pasado, el microrrelato remite desde el paratexto central a la imagen fotográfica. La trama introduce al lector en lo que podría ser una escena familiar, propia del ámbito doméstico, que se torna escalofriante, tenebrosa y macabra; con el desconcierto y la paradoja Esteban Erlés enfatiza la distancia con los componentes referenciales esperados, estetiza el horror y se polariza en universos extremos. Los componentes textovisuales monstruosos anidan en la cotidianeidad y están al servicio de la indagación sobre la identidad y los límites del sujeto; ambos revisten propiedades metacognitivas y permiten observar la realidad y tomar conciencia de la propia observación (López-Varela 2018: 22).

${ }^{8}$ Gran parte de estos estudios se han focalizado en los libros ilustrados infantiles. 
Como hemos visto en este microrrelato hipermedial, las prácticas artísticas se funden para explorar en qué medida pueden compartirse las experiencias humanas (Kattenbelt 2008: 20), impactando en el imaginario socio-cultural; modifican la perspectiva a partir de la cual se emprende la representación de las realidades cognitivo-emocionales (López-Varela, 2011: 98) y también la recepción, pues se ha de prestar atención al sentido que procede de la forma (Bouchardon, 2014, 40).

\section{Hibridación EN LA PROPUESTA DE Albert SOLOVIEV}

No detenemos en este momento en la obra de Albert Soloviev, ilustrador contemporáneo que se ha dado a conocer a través de las redes sociales, inicialmente a través de Twitter y Facebook (@albertSoloviev) -son excepciones los casos en los que el autor modifica el texto en el traslado de una plataforma a otra-, y posteriormente de Instagram. Aunque la mayor de sus ilustraciones, según ha confesado el escritor, son anónimas, encontramos algunos retratos de artistas, como el de la actriz colombiana Viviana Serna o el de la poetisa rusa Anna Ajmátova, que dibujó Modigliani. Ha ilustrado tanto libros completos, como El sexo de la risa y Grecia, de Irene X, como algunas portadas: Intranerso, de Carlos Miguel Cortés; Valkiria (Lapsus Calami), de Moisés Pérez; y Mordisquitos, de Alejandra Saiz.

Durante varios meses la plataforma Twitter fue para Soloviev como un cuaderno de notas, donde fue volcando las reflexiones sobre algunos de los temas que de manera obsesiva y recurrente presiden su proceso creativo: la identidad, la frustración, la soledad, las relaciones afectivas, la muerte, el suicidio, la condición de ser artista o el propio proceso creativo, etc. Aunque algunos de sus textos breves revisten un cierto tono biográfico y podrían ser considerados anotaciones diarísticas, su presencia junto a unas inquietantes ilustraciones les otorga una configuración narrativa dialógica. A medio camino entre la escritura aforística, la sentencia, el apunte diarístico o el pie de fotografía sus creaciones textovisuales condensan cierta ambigüedad.

Como iremos viendo, desde la hibridez textual genérica y mediante la transgresión visual, Soloviev apuesta por un espacio experimental que desborda los modos discursivos convencionales. La preeminencia visual de la imagen femenina dentro de la página, su estructura compositiva, posicionamiento central, nitidez focal y ausencia de marcos invitan 
al lector a formar parte de la composición narrativa (Nikolajeva y Scott 2001:62; Nodelman, 1988: 51). Teniendo en cuenta la posición frontal de los protagonistas de las ilustraciones y que la mayor parte son trazadas desde un ángulo medio desde el cual establecen una relación de igualdad con el receptor, la arquitectura compositiva visual aleja la posibilidad de que la imagen se convierta en un simple objeto de contemplación o en la plasmación de un concepto, acapara la atención del lector y demanda su implicación (Nodelman 1988: 151; Kress y van Leeuwen, 2006: 146).

Partiendo de la distinción que Krees y van Leeuwen plantean dentro de la función representacional entre imágenes conceptuales (intemporales) y relacionales (narrativas), que muestran acciones en desarrollo a través del movimiento y la mirada, en los microrrelatos hipermediales de Soloviev predominan estas últimas.

En mayo de 2013 comienza una serie numerada de ilustraciones en torno al motivo de la aceptación, casi todas ellas protagonizadas por mujeres. En la primera ilustración, fechada el 3 de mayo, los componentes verbales y visuales invitan con su ambigüedad al diálogo:

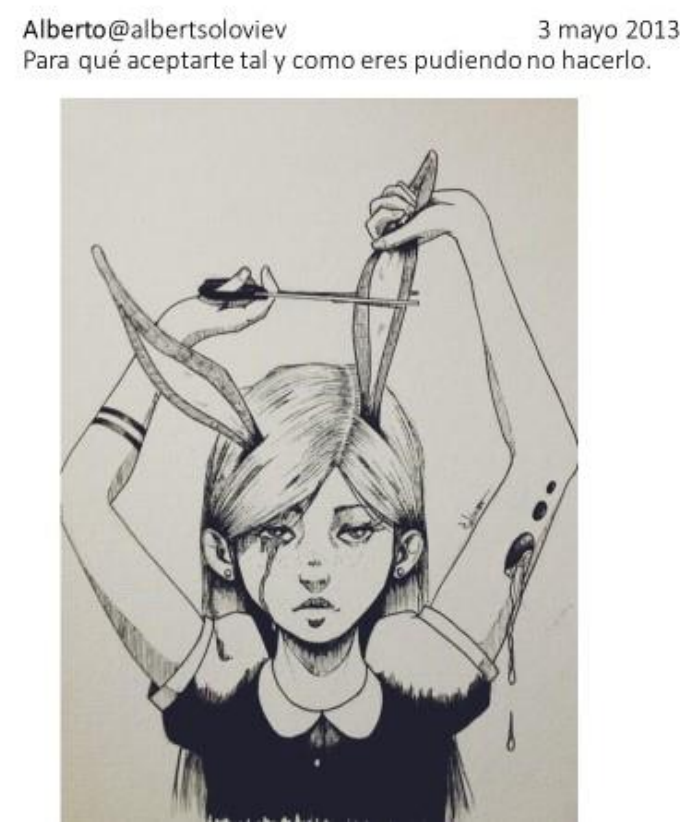

Ilustración 2

La voz narrativa se dirige a un tú, que bien puede ser la protagonista del dibujo o el lector/espectador; inicialmente la imagen de la muchacha suscita que ha podido ser obligada a comportarse de una determinada manera, según sugieren el ojo derecho y las orejas del 
conejo domesticable y delicado, que se impregna de cierta connotación sexual referido a la mujer; aunque la ausencia cromática no permite identificar si llora lágrimas o sangre, se impone la tesis de una posible dependencia afectiva; tras la contemplación sosegada del microrrelato hipermedial -no olvidemos la importancia del tiempo en la narración- se imponen algunos valores semánticos elididos y cobra fuerza la idea del rechazo y de la rebelión, que provoca el corte de las orejas.

Aunque el lector puede emprender una lectura independiente y autónoma de cada una de estas miniaturas narrativas, también puede realizar una lectura integrada de las mismas, como si de las piezas de un rompecabezas se tratara. Cuando la comparamos con la segunda ilustración que evoca la imagen de un unicornio, se alza otra interpretación: pueden ser adolescentes en busca de una identidad sexual. La falta de libertad, sugerida por la tristeza del semblante femenino y el agujero del brazo, cuyo interior parece poblado de gusanos, sugieren la sensación de vacío y de destrucción del yo y la muerte interior.

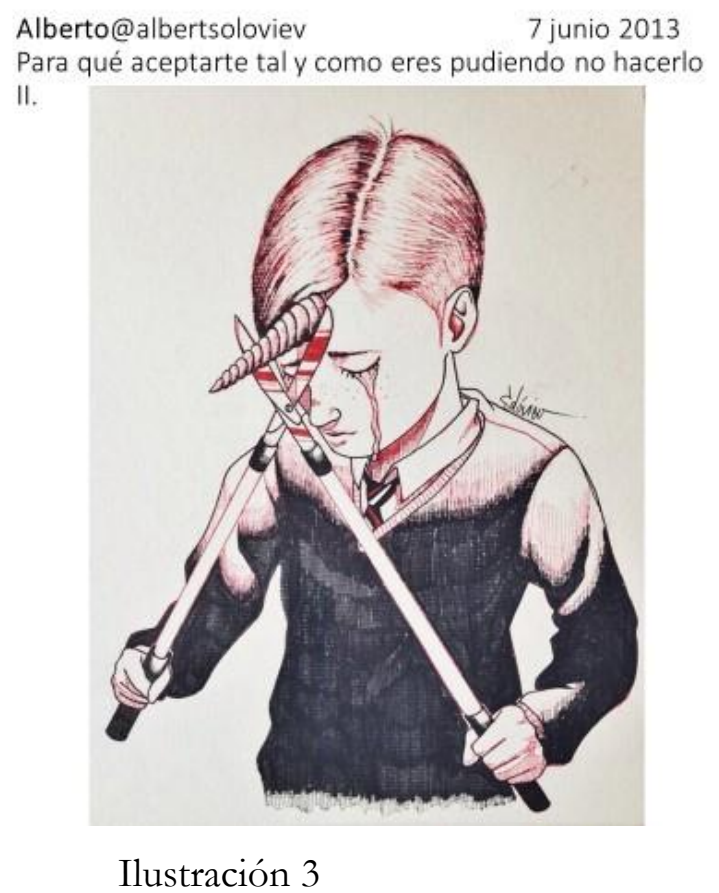

En la segunda ilustración de la serie, además de compartir también la ambigüedad del interlocutor, la presencia del cuerno en la frente se impregna de una connotación sexual; aunque la vestimenta del adolescente proyecta una posible pertenencia a una clase social burguesa y tradicional, la imagen del unicornio, con que la tradición mitográfica representa 
al caballo blanco con patas de antílope y barbas de chivo, asociada al movimiento LGTB, subraya la falta de aceptación y plantea la cuestión de la orientación sexual.

En la tercera composición asociada a la serie, fechada el 22 de septiembre del mismo año, el diálogo cambia.

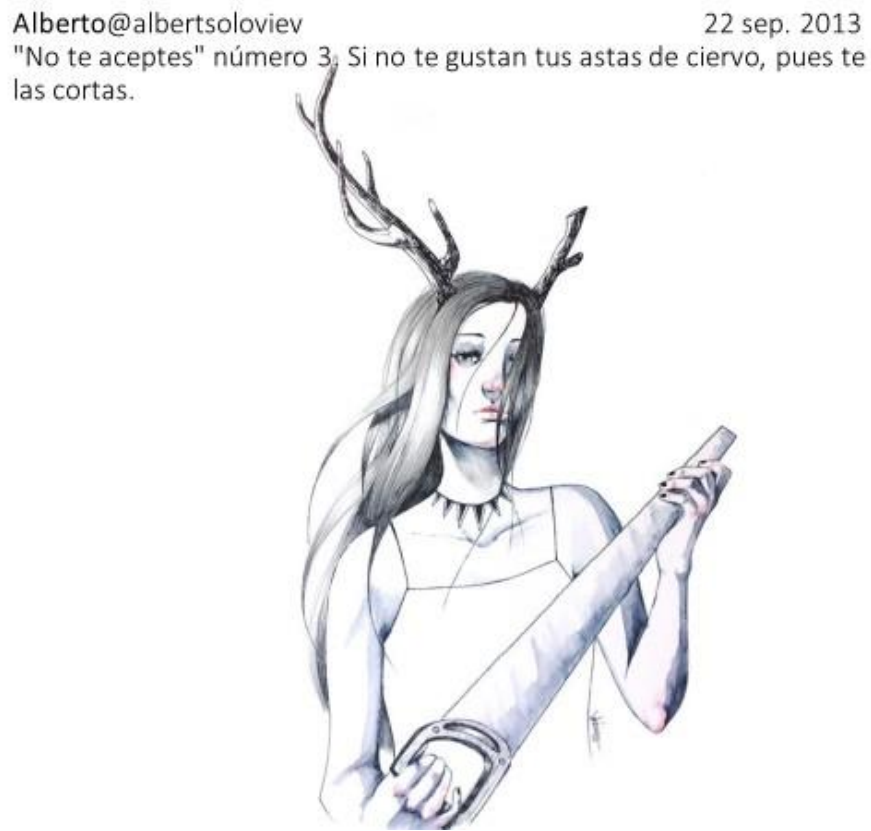

Ilustración 4

Si hasta el momento un texto idéntico revestía una formulación dubitativa, ahora se impregna de tono imperativo: "No te aceptes". La voz narrativa nuevamente es ambigua; al aparecer entre comillas sugiere que el emisor puede ser la joven, aunque podría serlo también un narrador, que se dirige simultáneamente al lector/espectador y a la protagonista. Si las dos microformas narrativas hipermediales anteriores mostraban el punto álgido de un proceso en el instante previo a la ejecución de la acción, lo que generaba mayor implicación afectiva en un proceso doloroso que se querría haber evitado, ahora el proceso está consumado. Las astas de los animales, que con su connotación de virilidad y de componente pasional sugieren una posible infidelidad, y la sierra se sitúan en línea de continuidad semántica con las composiciones de la serie y enfatizan la naturaleza dramática de la escena. En todas ellas sobresale el papel desempeñado por el dispositivo metafórico, que actúa como motor de la creación textovisual y revela su doble condición plástica y verbal; gracias a los semas comunes los límites del texto se trascienden y proyectan con fuerza en el lenguaje visual (Albaladejo, 2016: 55). 
Sin formar parte de la serie, encontramos otros microrrelatos hipermediales que bien podrían ser incluidos en la misma, como este: "Mi especialidad es hacerlo todo al revés" (23 de mayo de 2013):

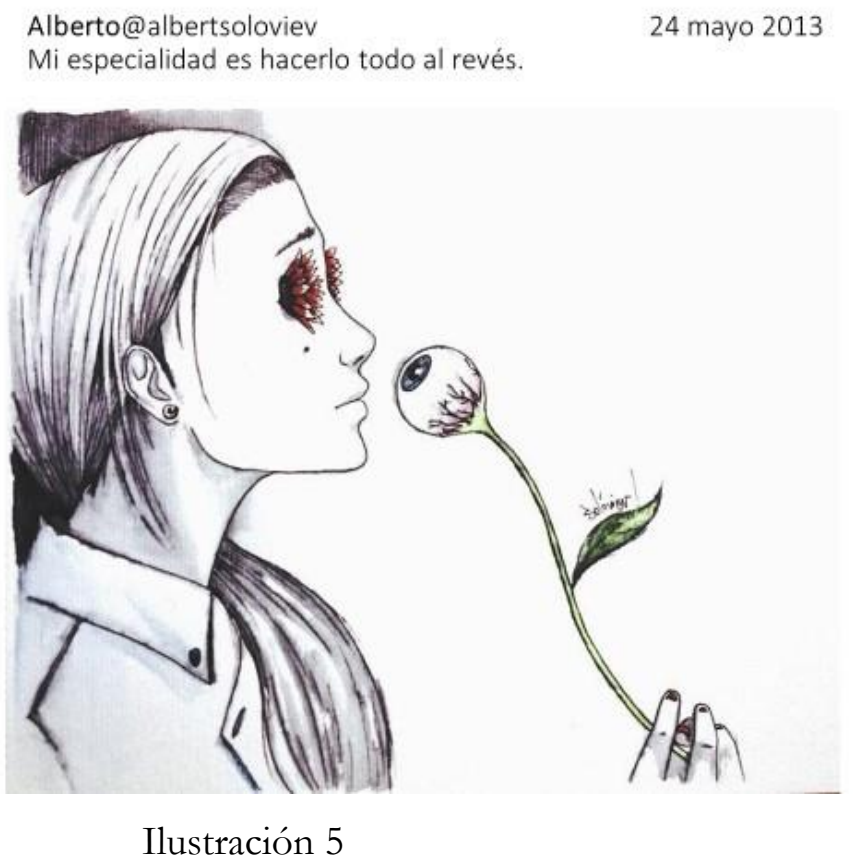

En este microrrelato hipermedial la ilustración es un elemento constructivo esencial de la trama, pues delimita uno de los posibles desenlaces que podría tener y facilita el despliegue cognitivo que permite alcanzar la descodificación del mensaje. La corola de una flor que podría ser un crisantemo, asociado a la muerte, ocupa la oquedad de los ojos e impide la visión. Si bien el texto invita a desplegar introspectivamente la percepción sobre el mundo interior, la ilustración la proyecta sobre el cuerpo como eje de referencia de la actuación perceptual del sujeto y sobre las sensaciones corporales que se derivan del ejercicio de la vista como órgano de mediación entre el mundo exterior y el interior, enfatizando la quiebra; la visión pesimista y autodestructiva por parte del protagonista deriva de la consideración y estima que un yo ajeno proyecta sobre el sujeto. Teniendo en cuenta que el cuerpo es el lugar donde el mundo se manifiesta y que actúa como umbral entre el sujeto y el mundo, la quiebra de la visión entraña la ruptura de la propia identidad y anula la adecuada captación de la significación de la realidad. Se subraya así la tensión entre la luz que deriva de la visión y la obscuridad en que el sujeto se encuentra. Este contraste aporta carga semántica y la significación se alza como fruto de la interacción entre ambos componentes, 
al tiempo que se acentúan los significados connotativos de afirmación (vida) / negación (escaso reconocimiento y poca autoestima).

También podría formar parte de la serie el micorrrelato hipermedial "¿Pero qué tontería es ésa de que no quieres cambiarme?” (21 de junio de 2103):

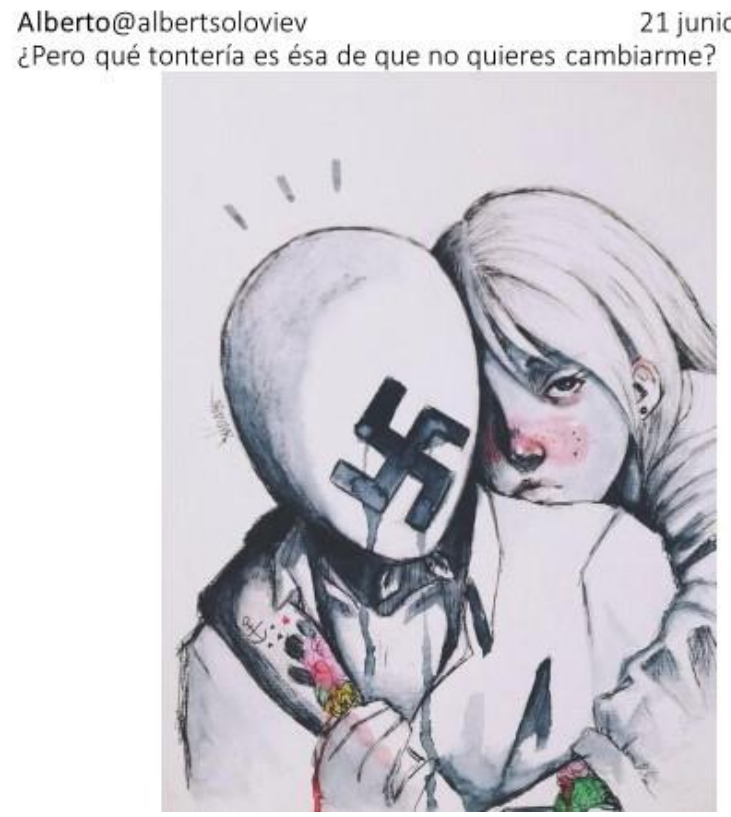

Ilustración 6

La adopción de un ángulo de observación singular y subjetivo de los acontecimientos confiere a este microrrelato hipermedial el rango de historia. El sujeto de la enunciación determina la estructura dialógica del discurso y señala el lugar que desempeña el tú, a partir del cual puede el lector observar los hechos narrados. La ambigüedad suscitada por el diálogo de los dos personajes es enorme y el lector no acierta a saber si es un diálogo en forma de monólogo interior o si, como en otras ocasiones, es un diálogo que se mantiene con él, mediatizado por la ilustración y por el componente verbal, pues no debemos olvidar que la formulación de una pregunta es un mecanismo para atraer la perspectiva del narratario y lograr que atienda a la verosimilitud de lo narrado. La imagen de la cruz gamada con sus connotaciones negativas (muerte/violencia) se libera del valor simbólico que le otorgó el Tercer Reich y se expande hacia la violencia machista. Sobresale dentro de la brevedad textual la fuerza narrativa que se deriva tanto de la presencia de un verbo de movimiento ("cambiarme") como de la naturaleza dialógica del relato; en este sentido conviene recordar que la narratividad es un rasgo constitutivo del género frente a otros géneros breves 
(aforismos, haikus o poemas en prosa) pues, como señala Andres-Suárez, "no hay microrrelato sin una historia, sin una trama, sin una acción sustentada en un conflicto y en un cambio de situación y de tiempo, aunque sean mínimos" (2007:18).

De manera progresiva la violencia de género va adquiriendo protagonismo en las creaciones de Albert Soloviev. Lo percibimos en la confesión de una mujer "Yo sólo echo de menos con sangre" (28 de junio de 2013,) que mantiene un rictus sereno y lleno de dolor, como podemos apreciar a través de las lágrimas y la sangre:

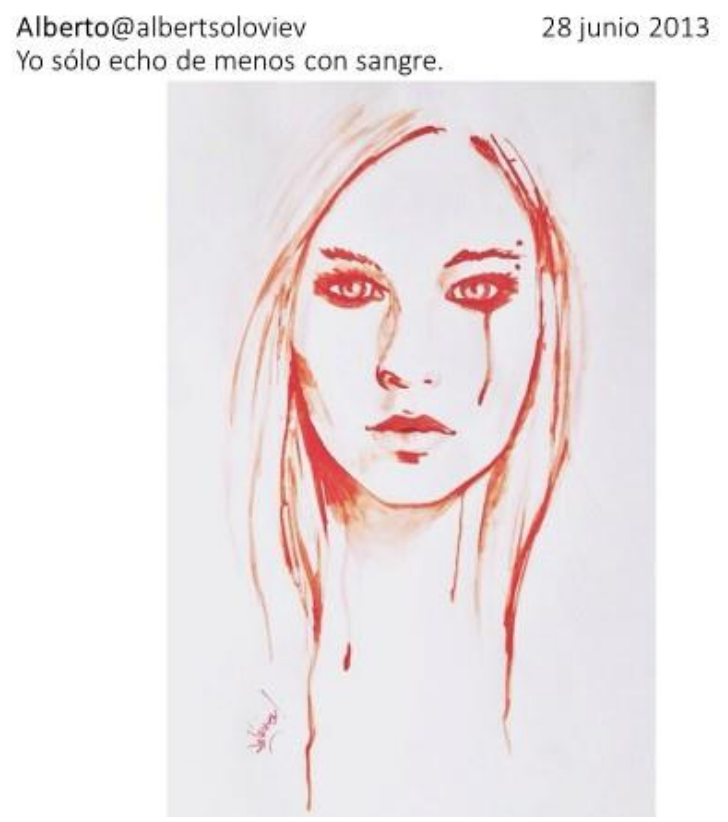

Ilustración 7

Traspasada por otros yoes, la voz subjetiva de un narrador en primera persona acoge en su seno a todos los yoes heridos y despliega gradualmente la voz de una sociedad herida por la violencia y por el maltrato, que no oculta su deseo de venganza.

Son varios los motivos que de manera reiterada presiden estas creaciones narrativas textovisuales: los ojos, las lágrimas, la cuerda, las flores, las mariposas, etc., y numerosas las ilustraciones que representan el acto voluntario de cerrar los ojos, aunque no siempre este acto adquiere idéntica significación. La cosificación de la mujer se nutre de distintos símbolos, como el juguete que subraya la ilustración en el microrrelato hipermedial "Yo también merezco que me abracen todos los días"”, le confesaba justo después de arrancarle la cara" (5 de julio de 2013): 


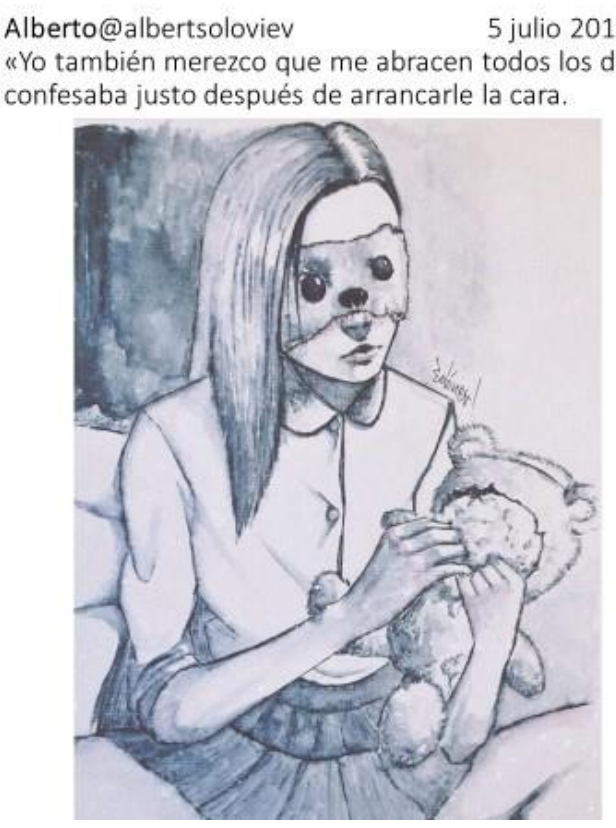

Ilustración 8

La ilustración es claramente ambigua: una niña juega con un oso de peluche o alguien juega con ella. Al tiempo que se alza metafóricamente la representación de la feminidad como objeto o juguete, se intensifica la plasmación textovisual del chantaje emocional. La subjetividad herida y postraumática de la muchacha, que cubre el rostro con la piel que le ha arrancado al muñeco que tiene entre las manos, se prolonga textualmente mediante la rememoración de algunas de las sensaciones asociadas al maltrato.

No faltan tampoco microrrelatos que inciden tanto en la verosimilitud probatoria de las lesiones físicas como en la inutilidad de los intentos de enmascarar y ocultar las marcas que la violencia deja en el rostro y en el cuerpo de la mujer, como percibimos a continuación: 

elegí mal.

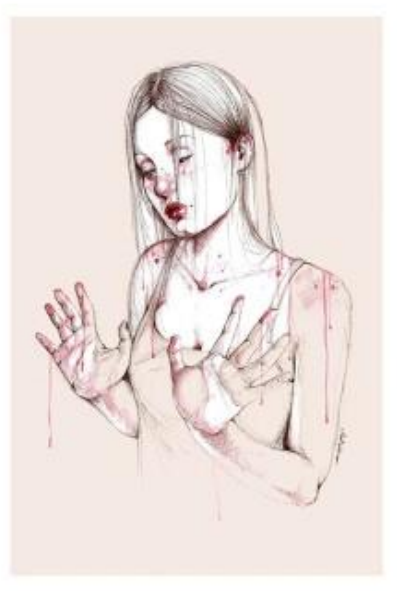

Ilustración 9

Frente al lenguaje deíctico de la fotografía que, según Barthes, no es más que "un canto alternado de «Vea, «Ve», «Vea esto», [...]” (1990: 32), las ilustraciones de Soloviev se anclan en la imaginación que busca ser compartida. Desde la perspectiva de la narratividad visual el predominio de vectores corporales (especialmente el rostro facial y en algún caso las extremidades superiores), es decir, de imágenes de reacción, demanda la involucración del lector en la trama narrativa.

Otros microrrelatos muestran las descalificaciones y humillaciones que incluyen tanto el lenguaje verbal (insultos, amenazas) como el no verbal (ademanes, miradas, tensión muscular), las cuales inciden en la sumisión con que el maltratador suele ejercer su poder sobre la víctima y esta tiende a naturalizar el desprecio y el agravio sufrido. Lo percibimos en las leyendas que aparecen escritas en la venda con que la muchacha cubre sus ojos: "espero que no te recuperes nunca", "la llorica", "ojalá estuvieras muerta", "puta", "la culpa es tuya", "te lo mereces". 


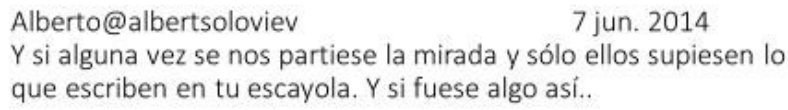

Alberto@albertsoloviev

7 jun. 2014

Y si alguna vez se nos partiese la mirada y sólo ellos supiesen lo que escriben en tu escayola. Y si fuese algo así..

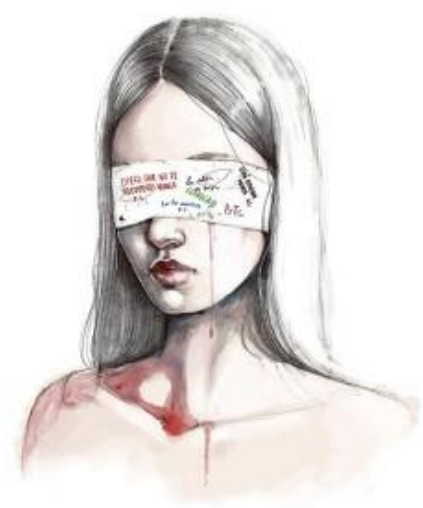

Ilustración 10

Otras miniaturas narrativas revelan el enojo y el deseo de venganza, como vemos en este microrrelato hipermedial, en el que la ruptura violenta de la estructura verbal encuentra clara correspondencia con la semántica de la oposición cromática rojo, blanco y negro de la ilustración:

Alberto@albertsoloviev

1 jun. 2015

A "ojo por ojo", no sé. Pero a "ojo por ojo por ojo por ojo" gano yo seguro.

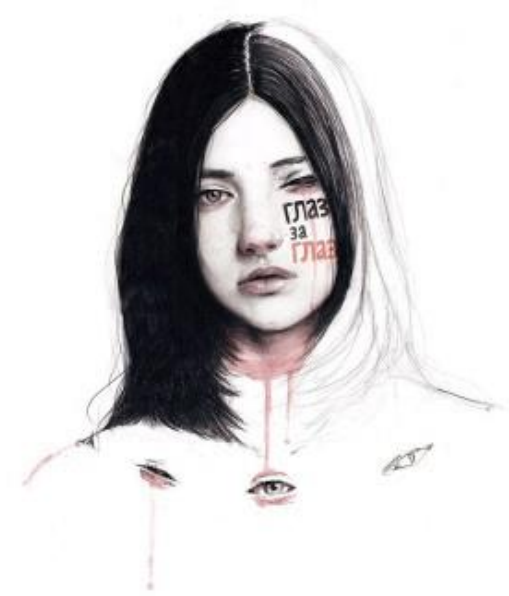

Ilustración 11 
Como vemos, la brevedad, la simplicidad léxica, la fragmentación textual, los silencios y el empleo del tiempo presente se ajustan de manera equilibrada a la condensación semántica y a la contención narrativa de las ilustraciones, a través de las cuales se percibe el infierno vivido por las víctimas de la violencia y de los abusos; estos microrrelatos hipermediales se convierten así en altavoz de todas las víctimas y cobran una dimensión oral invitando al lector a que adopte una posición.

Estos microrrelatos hipermediales son una forma plástica de plasmar la intensidad del daño afectivo y psíquico que sufren las víctimas, que podría desembocar en el suicidio; de modos diversos aborda Albert Soloviev la sintomatología que acompaña la victimización, como la disminución del nivel de interacción con el entorno social, la baja autoestima, la depresión o el aislamiento social:
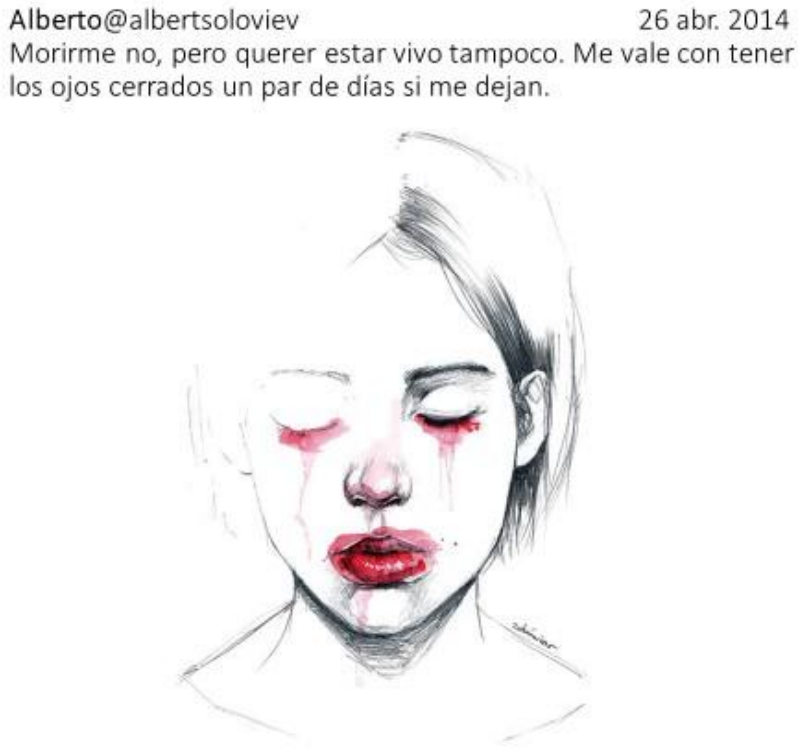

Ilustración 12

A través de la condensación expresiva del trazo, de la fragmentación cromática y de la contraposición agonística que delimitan los prolongados silencios de la página en blanco se alza con fuerza la voz narrativa de la imagen visual, que perfila la lucha entre el adentro del sujeto lírico-narrativo y el afuera de la denuncia social, entre la historia que se anhela contar y lo que se enmudece y calla. 

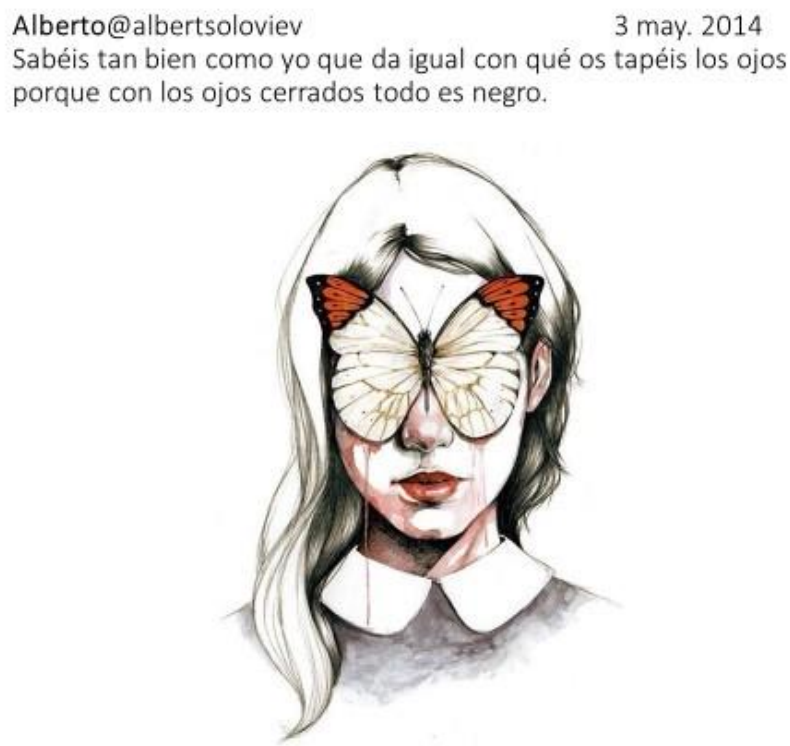

Ilustración 13

Tanto las prolongadas elipsis textuales y visuales como la potencia del motor metafórico (Albaladejo 2019) inciden en la denuncia de la invisibilización del maltrato; plasman una de las dificultades existentes para el reconocimiento de la violencia hacia las mujeres, el que deriva de la demanda de la constancia de herramientas (daños materiales) que lo hagan perceptible a los agentes sociales, lo que contribuye a la desestimación de las lesiones que no son perceptibles físicamente (Corsi 2011).

Como hemos estudiado, la condensación emotiva de la expresión facial, la preservación de la belleza, la inmortalización de la acción, el silencio del miedo y la fuerza expresiva del trazo enfatizan conceptualmente los temas y contradicciones que suscitan niveles de lectura más profundos: la fragilidad y vulnerabilidad de la mujer, la agresión y el maltrato, el vacío existencial, la soledad o la tristeza. Los microrrelatos hipermediales de Soloviev, al tiempo que representan la pérdida y la ausencia, la denuncia de la inocencia perdida y la intemperie de la condición femenina, muestran el dolor humano y provocan un efecto catártico, la purificación del alma. La voz narradora se erige en cronista de su tiempo que intercala mediante una estructura dialógica profundas reflexiones sobre la condición humana. Soloviev invita al lector a gozar de una experiencia estética que lo interpela y exhorta a reflexionar desde la disensión y la crítica, contribuyendo así a que la sociedad tome conciencia de esta lacra. 
BIBLIOGRAFÍA

Albaladejo, Tomás (2016): «Teoría de la Literatura y Estética», Laocoonte. Revista de Estética y Teoría de las Artes, 3, 3: 49-58.

Albaladejo, Tomás (2019): «El motor metafórico y la fundamentación retórico-cultural de su activación», Castilla. Estudios de Literatura, 10: 559-583.

Andres-Suárez, Irene (2007): «El microrrelato: caracterización y limitación del género. Mundos mínimos», en $\mathrm{M}^{\mathrm{a}}$ Teresa Gómez Trueba (ed.): El microrrelato en la literatura española contemporánea, Valladolid, Cátedra Miguel Delibes.

Barthes, Roland (1990): La cámara lúcida. Nota sobre la fotografía, Barcelona, Paidós Comunicación.

Barthes, Roland Le bruissement de la langue. Paris: Seuil, 1984. El susurro del lenguaje. Trad. C. Fernández Medrano. Barcelona: Paidós, 2009.

Blanchot, Maurice (2008): La conversación infinita, Madrid, La Arena Libros.

Borrás Castanyer, Laura (2005): Textualidades electrónicas. Nuevos escenarios para la literatura, Barcelona, Editorial UOC.

Bouchardon, Serge (2004): Le valeurheuristique de la littératurenumerique, Paris, Hermann.

Calvo Revilla, Ana (2017): «Microrrelato en red: intermedialidad y redes de interacción en la cultura textovisual. La obra de Juan Yanes y Araceli Esteves», en Lidia Bocanegra Barbecho y Ana García López (eds.): Con la Red / En la Red: creación, Investigación y Comunicación Cultural y Artística en la era Internet, Granada-New York, Universidad de Granada y Downhill Publishing (NY): 78-106.

Calvo Revilla, Ana (2019 en prensa): «Microrrelato hipermedial: simbiosis e hibridación semiótica y proyección significativa», en Teresa Gómez (ed.): Página y Pantalla: Interferencias microficcionales, Gijón, Ediciones Trea.

Carrión, Jorge (2011): Teleshakespeare, Madrid, Errata Naturae.

Corsi, Jorge (2011): «La violencia hacia las mujeres como problema social. Análisis de las consecuencias y de los factores de riesgo», Argentina, Documentación de Apoyo Fundación Mujeres. Asociación Argentina de Prevención de la Violencia Familiar. Delafosse, Émilie (2013): «Internet y el microrrelato español contemporáneo», Letral, 11: 7081. 
Escandell Montiel, Daniel (2014): Escrituras para el siglo XXI: literatura y blogosfera, Madrid/Frankfurt, Iberoamericana/Vervuert.

Gil González, Antonio J. (2012): +Narrativa(s). Intermediaciones novela, cine, cómic y videojuego en el ámbito hispánico, Salamanca, Universidad de Salamanca.

Gil González, Antonio J. y Pérez Bowie, Antonio (eds.) (2017): Ficciones nómadas. Procesos de intermedialidad literaria y audiovisual, Madrid, Pigmalion.

Gil González, Antonio J. y Pardo, Pedro Javier (eds.) (2018): Adaptación 2.0. Estudios comparados sobre intermedialidad. In honorem José Antonio Pérez. Bowie, Binges, Éditions Orbis Tertius.

Gómez Trueba, Teresa (2018): «Alianza del microrrelato y la fotografía en las redes: ¿Pies de fotos o microrrelatos?».en Ana Calvo Revilla (ed.), Elogio de lo minimo. Estudios sobre microrrelato y minificción en el siglo XXI, Madrid, Iberoamericana/Vervuert: 203-220.

Holtzman, Steven R. (1994): Digital Mantras. The languages of abstract and virtual worlds, Massachusetts, The MIT Press.

Kattenbelt, Chiel (2008): «Intermediality in theatre and performance: Definitions, perceptions and medial relationships», Revista de Estudios Culturales de la Universitat Jaume, I6, 1.

Kress, Gunther (2003): Literacy in the New Media Age, London y New York, Routledge.

Kress, Gunther y van Leeuwen, Theo (1996): Reading images: The grammar of visual design, London, Routledge.

López-Varela Azcárate, Asunción (2011): «Génesis semiótica de la intermedialidad: fundamentos cognitivos y socio-constructivistas de la comunicación», CIC. Cuadernos de Información y Comunicación, 16: 95-114.

López-Varela Azcárate, Asunción (2018): «El futuro de las narratologías híbridas II. A través del espejo de Lewis Carroll», Espacios transtliterarios. Hibridez, digitalidad, migración., en Susana Justo Barreira y Laura Pereira Domínguez (eds.): Santiago de Compostela: Universidade de Santiago de Compostela: 14-53.

Manovich, Lev (2005): El lenguaje de los nuevos medios de comunicación: la imagen en la era digital, Buenos. Aires, Paidós

Millán Barroso, Pedro Javier (2009): «La fotografía documental como microrrelato visual. Procesos instantáneos», en Salvador Montesa (ed.): Narrativas de la posmodernidad: del cuento al microrrelato, Málaga, AEDILE-Congreso de Literatura Contemporánea: 515527. 
Mitchell, William John Thomas (1994): Picture Theory: Essays on Verbal and Visual Representation, Chicago, Chicago University Press.

Moebius, William (1986): «Introduction to Picturebooks Codes», Word and Image, 2:141-158.

Mora, Vicente Luis (2015): «Fragmentalismo y fragmentarismo en la narrativa hispánica actual», Bitácora Diario de lecturas, 4 de octubre, en http://vicenteluismora.blogspot.com.es/2015/10/fragmentarismo-yfragmentalismo-en-la.html (13 de enero de 2019).

Müller, Jürgen (2006): «Vers l'intermedialité. Histoires, positions et options d'un axe de pertinence», Médiamorphoses, 16: 99-110.

Nikolajeva, Maria y Scott, Carole (2001): How Picturebooks Work, New York y Londres, Garland Publishing.

Nodelman, Perry (1988): Words about Pictures: The Narrative Art of Children's Picturebooks, Athens, The University of Georgia Press.

Noguerol Jiménez, Francisca (2008): «Minoficción e imagen: cuando la descripción gana la partida», en Irene Andres-Suárez y Antonio Rivas (eds.), La era de la brevedad: el microrrelato hispánico, Palencia: Menoscuarto: 183-206.

Rajewsky, Irina (2005): «Intermediality, Intertextuality, and Remediation: A Literary Perspective on Intermediality», Intermédialités: Histoire et théorie des arts, des lettres et des techniques / Intermediality: History and Theory of the Arts, Literature and Technologies, 6: 4-64.

Rivas, Antonio (2018): «Dibujar el cuento: relaciones entre texto e imagen en el microrrelato en red», en Ana Calvo Revilla (ed.): Elogio de lo minimo. Estudios sobre microrrelato y minificción en el siglo XXI, Madrid, Iberoamericana/Vervuert: 221-242.

Romero López, Dolores (2012): «De lo analógico a lo hipermedia», en Rafael Alemany Ferrer y Sagrario López Poza (eds.): Cibercultura i comparatisme. Alacant, Universitat d'Alacant, SELGYC, en http://www.cervantesvirtual.com/obra/ciberliteratura-icomparatisme-ciberliteratura-y-comparatismo/ (8 de enero de 2019).

Routhier, Élisabeth (2017): «Perspective intermédiale sur le motif de la disaparition. Enjeux d'une poétique de la remédiation chez Perec, Modiano et Nolan», Tesis doctoral. Université de Montréal.

Silva-Díaz Ortega, Cecilia (2005): Libros que enseñan a leer: álbumes metaficcionales y conocimiento literario, Tesis doctoral, Universidad Autónoma de Madrid.

Sipe, Lawrence R. (1998): «How Picture Books Work: A Semiotically Framed Theory of Text-Picture Relationships», Children's Literature in Education, 29, 2: 97-108. 
üe ACTIO NOVA: REVISTA DE TEORÍA DE LA LITERATURA Y LITERATURA COMPARADA, 3 (2019): 532-555 DOI: https://doi.org/10.15366/actionova2019.3.022

Vouillamoz, Núria (2000): Literatura e hipermedia. La irrupción de la literatura interactiva: Precedentes y crítica, Barcelona, Paidós.

Wölffin, H. (2011): Conceptos fundamentales de la Historia del Arte, Madrid, Espasa. 


\section{SOBRE LA AUTORA}

\section{Ana Calvo Revilla}

Profesora Titular de Teoría de la Literatura y Literatura Comparada en la Universidad CEU San Pablo, de Madrid. Ha dirigido también como Investigadora Principal (IP) el Proyecto de Investigación "MiRed (Microrrelato. Desafíos digitales de las microformas narrativas literarias de la modernidad. Consolidación de un género entre la imprenta y la red)" (FFI2015-70768-R), financiado por el Ministerio de Economía y Competitividad de España y el Fondo Europeo de Desarrollo Regional (FEDER), en el marco del Plan Estatal de Investigación Científica y Técnica y de Innovación Orientada a los Retos de la Sociedad. Ha coordinado 3 monográficos de referencia en el ámbito del microrrelato y la minificción: Epifanias de la brevedad. Microformas literarias y artísticas en la red (Visor, 2019); Elogio de lo minimo. Estudios sobre microrrelato y minificción en el siglo XXI (Iberoamericana/Vervuert 2018) y, junto a J. de Navascués, Las fronteras del microrrelato. Teoría y práctica del microrrelato español e iberoamericano (Iberoamericana/Vervuert 2012). Es directora de Microtextualidades. Revista Internacional de microrrelato y minificción (2017-).

Contact information: Email: crevilla.ihum@ceu.es 